\title{
CHESS COMPUTERS AND ENDGAME STUDIES 3
}

\author{
Brian Gosling \\ 36 Westwood Drive \\ Frome \\ Somerset \\ BA11 4JR England
}

I would like to thank Ken Whyld and Wlodek Proskurowski for their keen interest in my article "Chess Computers and Endgame Studies". As they both mention the Korolkov Study and the Hey study I will deal with their comments together.

Study No. 1: V. and M. Platov, 1908.

This study is not the prize winning study which was a favourite with Lenin. I did not wish to imply this when writing the article. I thought this was reasonably clear and I was only comparing them because of the role the Knight played in each position.

Study No. 2: V. Korolkov, 1948.

It is a mixed blessing to find that there are further corrections to the 1948 study. The position that Ken and Wlodek quote are essentially from the same study. Ken gives the initial position and the early moves to 5 . a4. This is the move that the study in Encyclopedia of Chess Endings (ECE) starts with but both positions are from the $2^{\text {nd }}$ prize winner in Uzbekistan in 1954. It confirms my earlier result that the 1948 study was indeed flawed. If I had known about the correction I would not have added my own. I agree with Wlodek that my correction is not as creative as the Korolkov's but it shows that the original 1948 position is drawn. This was the idea I wanted to convey to my readers.

As I understand it no one has a monopoly for a correction. If Korolkov were alive I would have made efforts to contact him. In passing, let me state that most composers have been extremely helpful in my work and do not seem to be threatened by my computer analysis.

Study No. 3: F. Hey, 1913.

I'm grateful to both writers for the information on what Hey really understood about this position. This correction along with others is incorporated in the 1992 edition of Test your Endgame Ability by Livshits/Speelman (Batsford). To be fair to the authors, there are over 500 studies in this book. One would not expect every study to be free from errors.

Finally I would like to deal with Wlodek's comment that my conclusions are too optimistic. I stand by my conclusions. New techniques are being developed all the time in both programming and increasing computer speeds. It was the development in the RISC technology which has led to new heights of achievement. By the year 2000 computer analysis would have solved all Endgame studies.

\section{KLING-HORWITZ POSITIONS}

\author{
John Roycroft \\ 17 New Way Road \\ London \\ England NW9 6PL
}

Just one point arising from the extensive ICCA Journal article on Timman vs. Speelman [Vol. 15, No. 1, pp. 2839]. The comment after 72. Bd6 reads "This position resembles the fourth exit ...". Well, a position either is an 'exit' or it isn't. Possibly there is a fifth (or even more) beyond the four identified in 1985, but this has yet to be demonstrated. Optimal lines from the position after 72. Bd6 must give Black the chance of a Kling-Horwitz $(\mathrm{K} \& \mathrm{H})$ position, for example: 
when we have precisely the fourth exit, i.e., a position from which the defender can be stopped from resuming such a position.

As a postscript let me mention that psychologists have yet to agree on the nature of problem-solving difficulty, except that it is a speciality of humans. So when will the first psychologist realise that confrontations such as the Timman vs. Speelman ending offer opportunities for attacking precisely this question, using the appropriate extant databases as readymade infallible yardsticks?

\title{
ENDGAME SOURCE CODE GOES PUBLIC
}

\author{
Lewis Stiller \\ CNLS / MS B258 \\ Los Alamos National Laboratory \\ Los Alamos, NM 87545
}

The readers of this Journal may be interested in the fact that I have found a stable anonymous ftp site for the source code to create endgame databases. [See, e.g., ICCA Journal, Vol. 14, No. 3, pp. 129-134; Vol. 14, No. 4, pp. 198-201; Vol. 15, No. 1, pp. 16-18 for some of the recent results. - Eds.]

The anonymous ftp site is cmns.think.com (131.239.2.100) in archives/chess/snarc.public. I thank Thinking Machines Corporation for donating the ftp site.

I hope that this publicity encourages other implementations of my code (porting to other architectures).

\author{
Derek Oldbury \\ 4 Farm Close \\ Kingskerswell \\ Devon \\ England TQ12 5BT
}

ALPHA-BETA: A DISK MAGAZINE

The magazine's aim is to provide an informal link between the game-playing public and the specialised Societies which cater for the expert. This we do by publishing contact addresses of National and International groups; also, sources from which books and journals and equipment may be bought; also, a Calendar of important events. Increased membership of the various Associations is a prime target.

Additionally, we plan to run feature articles on the various games, to introduce the beauties of each game to players of other thinking games. We can include computer programs which play the game; arguably the best method of introducing a game to a newcomer, since it circumvents the need to purchase equipment before giving the game a trial! Where appropriate, we publish listings and discussions on how to program computer games - but this is about as far as we can go. We are not experts in all games. We need those dedicated groups and specialist Societies to contribute some interesting material (on disk, please), thus giving us a helping hand to propagate their activities. A reciprocal concept.

The project is still in its infancy. For those interested, the rates of subscription are: $\mathfrak{f 1 5}$ sterling per year (please add enough for bank charges if paying in a different currency), or $£ 4$ for a single issue. The magazine is published quarterly. 